\title{
IMPROVING THE PROCESS OF ANALYSING THE CAUSES OF PROBLEM BY INTEGRATING THE ISHIKAWA DIAGRAM AND FAHP METHOD
}

\author{
Andrzej PACANA ${ }^{1 *}$, Dominika SIWIEC ${ }^{2}$ \\ ${ }^{1}$ Rzeszow University of Technology, Faculty of Mechanical Engineering and Aeronautics, Rzeszow, Poland; \\ app@prz.edu.pl, ORCID: 0000-0003-1121-6352 \\ ${ }^{2}$ Rzeszow University of Technology, Faculty of Mechanical Engineering and Aeronautics, Rzeszow, Poland; \\ d.siwiec@prz.edu.pl, ORCID: 0000-0002-6663-6621 \\ * Correspondence author
}

Purpose: The analysis process of the causes of the problem by often used the Ishikawa diagram is not effective when knowledge is lacking with regard to the particular causes and their validity about the problem. Moreover, its subjectivity is affected by the people undertaking the analysis. The aim of this paper is to reveal ways of improving the analysis process of problem causes by utilising the new method of integrated techniques, i.e.: Ishikawa diagram and FAHP method.

Design/methodology/approach: An analysis process of problem causes was made by utilizing the integrated techniques, i.e.: Ishikawa diagram and FAHP method. The problem was identified after the FPI method, and it was a linear indication on the bearing cover from 410 steel.

Findings: It was shown that implementing the FAHP method in the Ishikawa diagram allows a numerical analysis of the main causes of the problem.

Research limitations/implications: Future analysis should be undertaken by applying the 5Why method, in order to fully identify the root cause of the problem.

Practical implications: A new method can be used to precisely and reliably analyse different types of problems.

Social implications: This method is an effective tool that supports the process of analysing the causes of the problem, and thus the process of making multi-criteria decisions.

Originality/value: The article proposes a new method for integrating analysis techniques, i.e. the Ishikawa diagram and the FAHP method, which can be effective in precisely and reliably assessing the causes of the problem.

Keywords: quality management, mechanical engineering, linear indications, Ishikawa diagram FAHP method.

Category of the paper: research paper, technical paper, conceptual paper. 


\section{Introduction}

Traditional methods and tools of quality management, called also quality management techniques, are a simple and effective way to analyze different types of problems. These techniques allow identifying the causes of problem in enterprises and industrial processes (Pacana et al., 2019; Siwiec et al., 2019). One of these is the Ishikawa diagram. The Ishikawa diagram, also called the fishbone diagram or causes and effects diagram, is a traditional tool of quality management as it allows visualization (Lira et al., 2017). Ishikawa diagramming has been applied to analyse problems and to identify the potential causes of their occurrence (Pacana et al., 2019). This diagram can be created, for example, during brainstorming (Jalal et al., 2019). After created the Ishikawa diagram and pointing out the potential and main causes, the 5Why method is often subsequently applied in order to point toward the root of the problem (Pacana et al., 2019a, 2019b). However, it is important to genuinely identify the root cause, as a wrongful identification wastes resources and time. Doing so can be problematic in view of a large number of cause problems, and because of the subjectivity that can arise during brainstorming. In order to eliminate the restrictions of the Ishikawa diagram, it was concluded that it is effective to propose a numerical method of analysing the causes of occurrence the problem that will identify, order and present in a graphical way the potential causes of the problem by way of:

- analysing the importance and influence of the potential causes of the problem,

- showing in a measurable way (numerical) which of the causes holds the greatest influence on the problem occurrence (i.e. main cause),

- taking into account the subjectivity of those making the choice.

In view of the restrictions imposed by the non-numerical nature of the Ishikawa diagram, a method for weighing the causes of the problem should be incorporated. A review of the selected literature items shows that the Ishikawa diagram has been applied to analyse the influence of the potential causes of the problem on the occurrence of the problem and that it has been integrated with, for example, quality management techniques (Pacana et al., 2019a, 2019b), logistic regression or simulation platforms (Lira et al., 2017; Liu et al., 2017; Batzias, 2012). However, the mathematical way of assessing the validity of the relationship of potential causes was not analysed, and such an approach could better show which of the causes is the actual main cause of the problem. What is more, the subjectivity of the persons who are establishing the potential causes of problem during the brainstorming session was not included.

Analysis of a large number of the factors affected by subjectivism is possible by applying the fuzzy multi-criteria hierarchical analysis of decision problems (Fuzzy Analytic Hierarchy Process, i.e. FAHP). Therefore, it is reasonable to hold that integrating the Ishikawa method and the FAHP method allows precise numerical identification of the main causes of the problem and a consideration of the subjectivism of the decision-maker. It must be recalled that the FAHP 
method was built upon combining the AHP method and fuzzy logic. In the real world, the FAHP method has been found useful in solving decision problems containing contradictory criteria and burdened with uncertainty. Therefore, the FAHP method is a tool that allows the analysis of imprecise criteria (Chang, and, Dong, 2017; Ligus, 2017).

The review of the latest positions of the literature of the subject shows that the FAHP method has been applied in order to calculate the criteria and to determine their validity (Khorramrouz et al., 2019; Zhang et al., 2019; Omrani et al., 2019). Also, the FAHP method has been integrated with other techniques, for example, the AHP method (Wang, 2019; Ridcha et al., 2019; Balist et al., 2019), geographical information systems (GIS) (Rodcha, 2019; Balist, 2019; Ramandi et al., 2018), the TOPSIS (Balist et al., 2019, Omrani et al., 2019), weighted least squares kernel machine ( $\mathrm{RBF}$ - kernel of the radial base function) to calculate the final result (Sehra et al., 2019) or with the fuzzy focus analysis (FCA) to modified the weight (Lyu et al., 2019). After a review of the literature of the subject, it was concluded that the FAHP method has application in the cause of analysis of decision problems in which many criteria are encountered.

It can be pointed out that the root method for collecting these criteria for analysis is, among other traditional methods, brainstorming. However, as concluded after the selected positions of the literature review, the FAHP method was not integrated with the Ishikawa diagram. Therefore, we chose to ascertain the effectiveness of combining the integrated Ishikawa diagram with the FAHP method in order to improve the process of analyzing the causes of the problem and to reliably and mathematically select the main causes of the problem. The aim of this work, therefore, is to improve the analysis process of problem causes by applying the new, not practiced method of integrated techniques, i.e. Ishikawa diagramming and FAHP method. The motivation to integrate the Ishikawa diagram with the FAHP method was to improve the process of analysing by taking into account decision-maker subjectivism. In the work, the process is demonstrated by assessing the root cause of the failure of a bearing cover made of 410 steel as revealed in a case study in an enterprise located in the Podkarpacie region in which the non-destructive test of the products was made. On the product, via the fluorescent method (FPI), a linear indication was identified, and the actual root cause out of many possible causes had to be identified.

\section{Method}

In the first steps of problem assessment, an Ishikawa diagram was made. This diagram, also called the cause-effect diagram, is graphical. In the main part of the diagram, the analysed problem was noted (linear indication). Then, to the basic Ishikawa categories $(5 \mathrm{M}+\mathrm{E})$, i.e.: man, measure, method, material, machine, environment and management (Pacana et al., 2019), the potential causes of problem were identified through brainstorming. In view of the similar causes pointed for the categories of method and material, these categories and causes were noted together. To the potential causes, intermediate causes were noted. After creating the 
Ishikawa diagram and identifying the potential and intermediate causes of the problem, in order to identify reliably and measurably the main causes of the problem, the FAHP method was then applied. In the first steps, according to the Saalty fuzzy scale (Table 1), which utilises a subjectivity score, each identified cause was rated.

Table 1.

Saalty fuzzy scale

\begin{tabular}{|c|c|c|c|}
\hline description & $\begin{array}{c}\text { fuzzy } \\
\text { number }\end{array}$ & triangular fuzzy scale & $\begin{array}{c}\text { inverse of the fuzzy triangular } \\
\text { scale }\end{array}$ \\
\hline Equally important & 1 & $(1,1,1)$ & $(1,1,1)$ \\
\hline Slightly more important & 3 & $(1,3,5)$ & $(1 / 5,1 / 3,1)$ \\
\hline important & 5 & $(3,5,7)$ & $(1 / 7,1 / 5,1 / 3)$ \\
\hline Much more important & 7 & $(5,7,9)$ & $(1 / 9,1 / 7,1 / 5)$ \\
\hline Absolutely more important & 9 & $(7,9,9)$ & $(1 / 9,1 / 9,1 / 7)$ \\
\hline
\end{tabular}

The result of each comparison of the causes of occurrence of the problem was a decisionmaker subjectivity score that was shown as a triangular fuzzy scale. Clear weights were then calculated from fuzzy comparative matrices (1-3) (Ligus, 2017; Mir, and Padma, 2016; Radionovs, and Užga-Rebrovs, 2016):

$$
S_{i}=\sum_{j=1}^{m} M_{g i}^{j} \otimes\left[\sum_{i=1}^{n} \sum_{j=1}^{m} M_{g i}^{j}\right]^{-1}
$$

where,

$$
\sum_{j=1}^{m} M_{g i}^{j}=\left(\sum_{j=1}^{m} l_{j}, \sum_{j=1}^{m} m_{j}, \sum_{j=1}^{m} u_{j}\right)
$$

and

$$
\left[\sum_{i=1}^{n} \sum_{j=1}^{m} M_{g i}^{j}\right]^{-1}=\left(\frac{1}{\sum_{j=1}^{m} u_{j}}, \frac{1}{\sum_{j=1}^{m} m_{j}}, \frac{1}{\sum_{j=1}^{m} l_{j}}\right) .
$$

After collecting the results, the weight of fuzzy values was calculated, where the method of fuzzy values comparison $(\mathrm{u}, \mathrm{m}, \mathrm{l})$ was used for each criterion $(5 \mathrm{M}+\mathrm{E})$ by applying the formula (4) $[15,20]$ :

$$
V\left(M_{1} \geq M_{2}\right)=\operatorname{hgt}\left(M_{1} \cap M_{2}\right)=\left\{\begin{array}{c}
1, \text { if } m_{1} \geq m_{2} \\
0, \text { if } l_{2} \geq u_{1} \\
\frac{l_{2}-u_{1}}{\left(m_{1}-u_{1}\right)-\left(m_{2}-l_{2}\right)}, \text { others. }
\end{array}\right.
$$

Next, a comparison was made of the minimum values that were the general results to each the Ishikawa criterium (5) []14,15]: 


$$
V\left(M \geq M_{1}, M_{2}, \ldots, M_{k}\right)=\min V\left(M \geq M_{i}\right), i=1,2, \ldots, k
$$

The normalization of the results (obtained values) was made in which the obtained minimum values were divided by the sum of these minimum values for the analysed criterion. The sum of the normalized values for each criterium should be equal to the 1 value. In the last step, the obtained results were assessed.

\section{Results}

The potential causes of the linear indications identified on the bearing cover are shown in the Ishikawa diagram (Figure 1). After the Ishikawa diagram was constructed, based on the Saaty fuzzy scale, a comparative analysis and assessment were performed for each of the causes in terms of each Ishikawa category to which these were assigned (Table 2). The FAHP method was then applied (Table 3, Table 4). After the generation of mathematical weighting, the main causes of the problem were selected from potential causes. These included:

- failure to comply with labour standards,

- no current procedures/instructions in place,

- inappropriate work pace during production,

- wrong machine parameters,

- worn out machinery,

- old machinery,

- incorrectly selected tools,

- pollution,

- bad measuring tools,

- uncalibrated measuring tools.

The case study shows that the combined use of the Ishikawa diagram and FAHP method is an effective approach and allows a mathematical analysis of the causes of the problem taking into account the subjectivity of the decision-maker.

\section{Conclusion}

The traditional quality management technique - Ishikawa diagramming - can be insufficient when a problem needs to be pointed out in a precise and unequivocal way, Hence, it must be amended by an approach that gives an end result that is precise and mathematical hence, the application of Ishikawa diagramming and the FAHP (Fuzzy Analytic Hierarchy 
Process) method. In this paper, the combination was used to provide a solution to a case study of bearing cover manufacturing in an enterprise located in Podkarpacie. The aim was to improve the analysis process of causes. Herein, firstly, Ishikawa diagramming was undertaken based on the Ishikawa rule $(5 \mathrm{M}+\mathrm{E})$, i.e. man, method, machine, management, material and environment. After creating the Ishikawa diagram and identifying the potential and intermediate causes of the problem, in order to identify in a reliable and measurable way the main causes of the problem, FAHP methodology was applied. After analysis, it was concluded that the main causes of the problem could be selected from potential causes such as failure to comply with labour standards, no current procedures/instructions being in place, inappropriate work pace during production, wrong machine parameters utilised, worn-out machinery, old machinery, incorrectly selected tools, pollution, bad measuring tools, uncalibrated measuring tools. Thus, the number of potential source causes was minimised so that further investigation could occur. Hence, using the method of the Ishikawa integrated diagram combined with the FAHP method has improved the process of analyzing the causes of the problem, taking into account the subjectivity of the decision-maker and allowing for an identification of the root causes of the problem. In future work, in order to make a more effective analysis of the problem, to the sequence of Ishikawa diagram and FAHP method, it will be necessary to add the 5Why method, in order to narrow again the list of potential error sources.

\section{References}

1. Balist, J., Heydarzadeh, H., Salehi, E. (2019). Modeling, Evaluation, and Zoning of Marivan county Ecotourism Potential using Fuzzy Logic, FAHP, and TOPSIS. Geographica Pannonica, 23(1), 47-63.

2. Chang, Y., Dong, S. (2017). Study on post evaluation of high-speed railway based on FAHP and matlab simulation calculation. Tehnicki Vjesnik-Technical Gazette, 24(6), 1749-1758.

3. Khorramrouz, F., Kajabadi, N.P., Galankashi, M.R. et al. (2019). Application of fuzzy analytic hierarchy process (FAHP) in failure investigation of knowledge-based business plans. SN APPLIED SCIENCES, 1(11), 1-13.

4. Ligus, M. (2017). Evaluation of Economic, Social and Environmental Effects of LowEmission Energy Technologies Development in Poland: A Multi-Criteria Analysis with Application of a Fuzzy Analytic Hierarchy Process (FAHP). ENERGIES, 10(10), 1-20.

5. Lira, L.H., Hirai, F.E., Oliveira, M. et al. (2017). Use of the Ishikawa diagram in a casecontrol analysis to assess the causes of a diffuse lamellar keratitis outbreak. Arquivos Brasileiros De Oftalmologia, 80(5), 281-284. 
6. Liu, K., Wang, Y., Lin, L. et al. (2017). An Analysis of Impact Factors for Positioning Performance in WLAN Fingerprinting Systems Using Ishikawa Diagrams and a Simulation Platform, MOBILE INFORMATION SYSTEMS, 1-20.

7. Lyu, H.M., Shen, S.L., Zhou, A. et al. (2019). Data in flood risk assessment of metro systems in a subsiding environment using the interval FAHP-FCA approach. DATA IN BRIEF, 26, 1-7.

8. Mir, S.A., Padma, T. (2016). Evaluation and prioritization of rice production practices and constraints under temperate climatic conditions using Fuzzy Analytical Hierarchy Process (FAHP). Spanish Journal of Agricultural Research, 14(4), 1-13.

9. Omrani, S., Jafari, M., Mansori, A. (2019). Analysis of Financial Performance of Cement Industry Manufacturing Companies in Tehran Stock Exchange Using the FAHP Technique and the TOPSIS Method. Independent Journal Of Management \& Production, 10(2), 512-536.

10. Pacana, A., Siwiec, D., Bednárowá, L., Hajduová, Z. (2019). Wybrane metody zarządzania jakością stosowane do oceny druku etykiet. Przemyst Chemiczny, 98(1), 110-112.

11. Pacana, A., Siwiec, D., Lucia, B. (2019). Analysis of the incompatibility of the product with fluorescent method. METALURGIJA, 58(3-4), 337-340.

12. Radionovs, A., Užga-Rebrovs, O. (2016). Fuzzy Analytical Hierarchy Process for Ecological Risk Assessment. Information Technology and Management Science, 19, 16-22.

13. Ramandi, M.M., Cheshme, B.G. (2018). Possess of locating the elementary schools using combined FAHP-Fuzzy logic in the GIS. Ukrainian Journal Of Ecology, 8(1), 255-265.

14. Rodcha, R., Tripathi, N.K., Shrestha, R.P. (2019). Comparison of Cash Crop Suitability Assessment Using Parametric, AHP, and FAHP Methods. LAND, 8(5), 1-24.

15. Sehra, S.K., Brar, Y.S., Kaur, N. et al. (2019). Software effort estimation using FAHP and weighted kernel LSSVM machine. SOFT COMPUTING, 23(21), 10881-10900.

16. Siwiec, D., Bednárowá, L., Pacana, A., Zawada, M., Rusko, M. (2019). Wspomaganie decyzji w procesie doboru penetrantów fluorescencyjnych do przemysłowych badań nieniszczących. Przemyst Chemiczny, 98(10), 1594-1596.

17. Zhang, J., Chen, X., Sun, Q. (2019). A Safety Performance Assessment Framework for the Petroleum Industry's Sustainable Development Based on FAHP-FCE and Human Factors. SUSTAINABILITY, 11(13), 1-20. 


\section{Appendix}

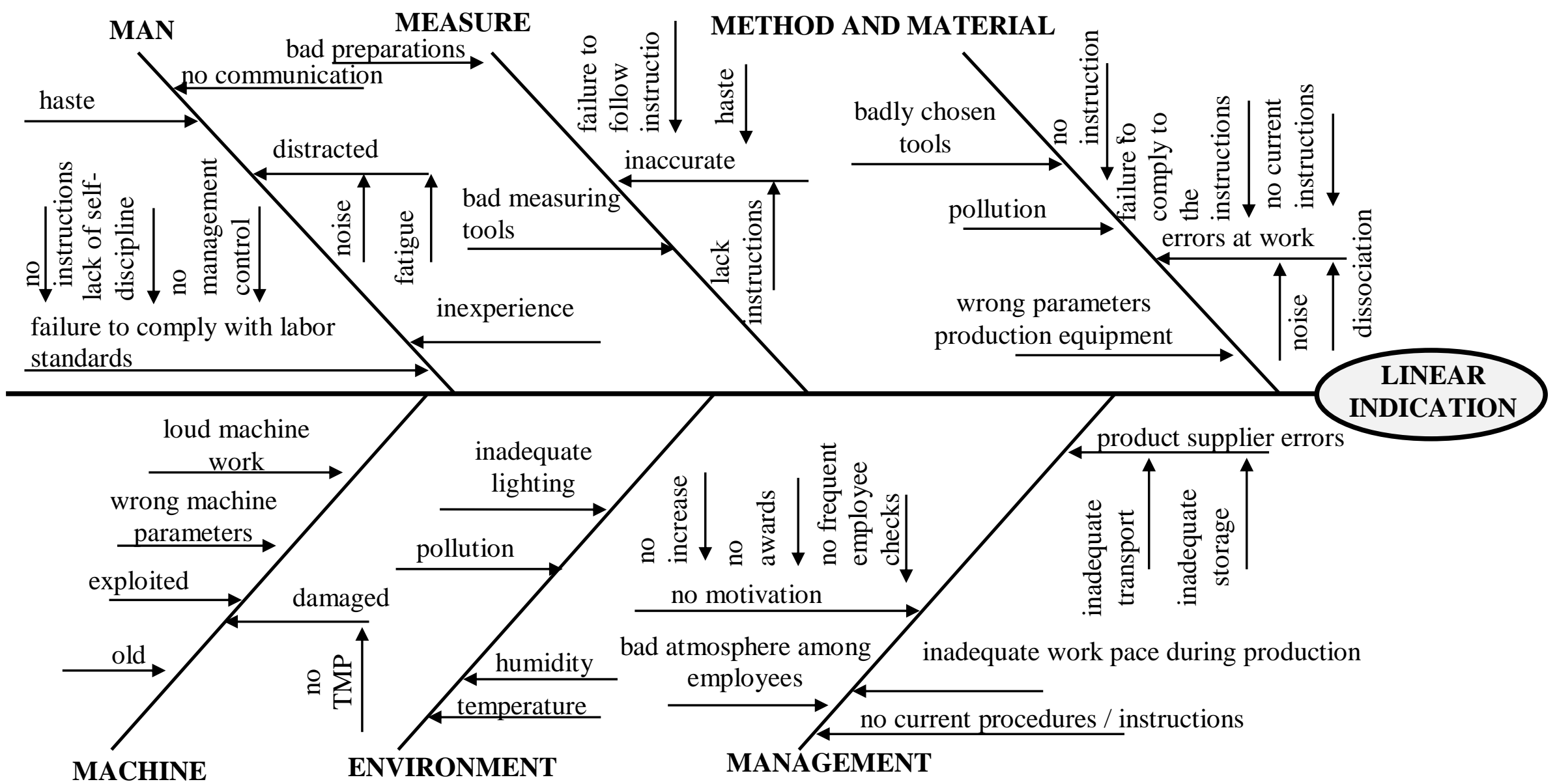

Figure 1. Ishikawa diagram for the linear indication problem. 
Table 2.

Assessment matrices of Ishikawa diagram criteria and potential causes of the problem

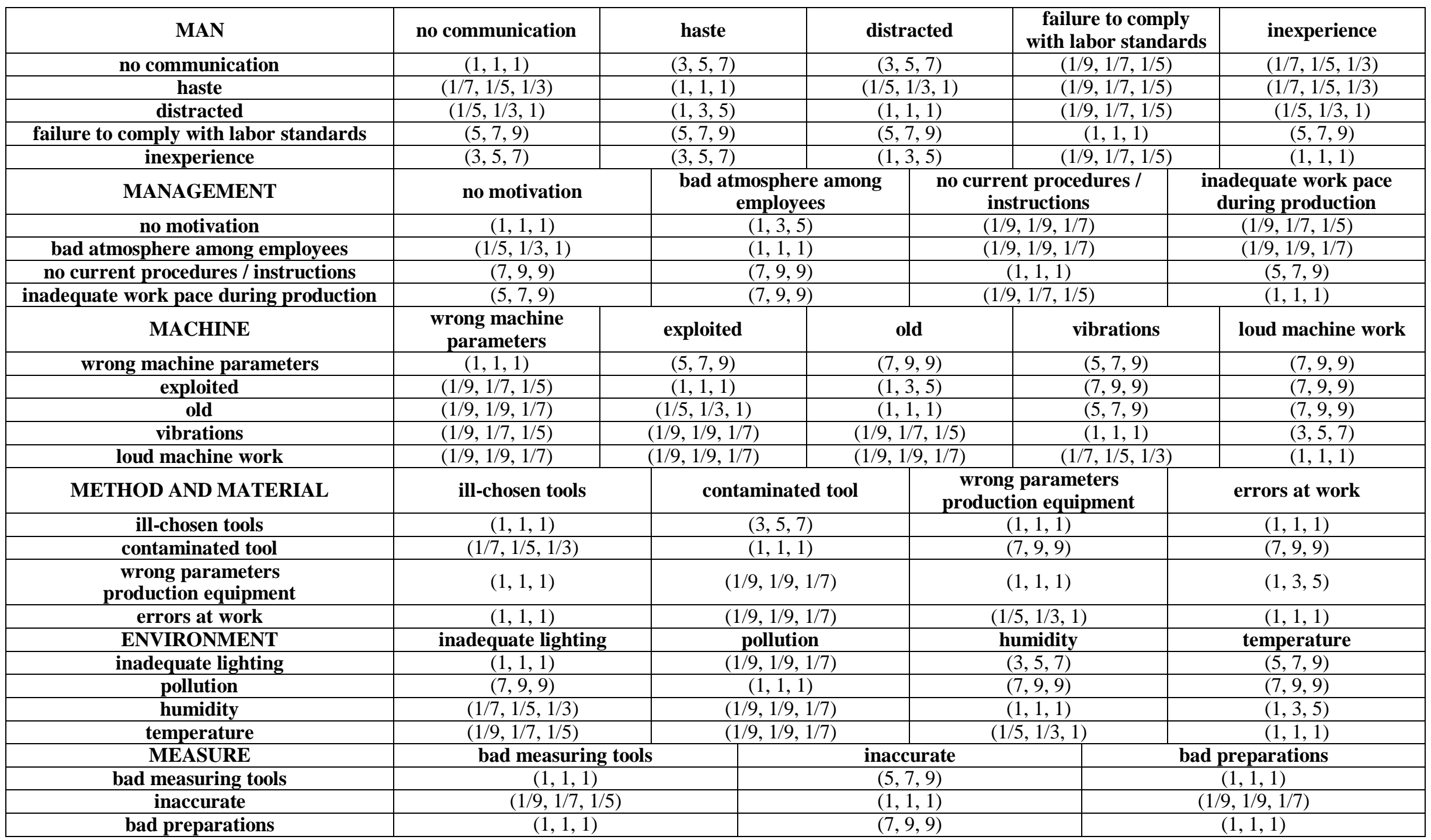


Table 3.

The results of the FAHP analysis and the importance of the causes of the problem

\begin{tabular}{|c|c|c|c|c|c|}
\hline MAN & symbol & 11 & m1 & u1 & WEIGHT \\
\hline no communication & M1 & 0.1115 & 0.2212 & 0.4530 & 0,240 \\
\hline haste & M2 & 0.1551 & 0.3433 & 0.7165 & 0,339 \\
\hline distracted & M3 & 0.1217 & 0.2670 & 0.5683 & 0,286 \\
\hline failure to comply with labour standards & M4 & 0.0172 & 0.0257 & 0.0445 & 0 \\
\hline inexperience & M5 & 0.0774 & 0.1428 & 0.2883 & 0,135 \\
\hline MANAGEMENT & symbol & 11 & m1 & u1 & WEIGHT \\
\hline $\begin{array}{c}\text { no motivation } \\
\end{array}$ & M1 & 0.2364 & 0.3541 & 0.5441 & 0,4219 \\
\hline bad atmosphere among employees & M2 & 0.2866 & 0.4494 & 0.6530 & 0,57807 \\
\hline no current procedures / instructions & M3 & 0.0239 & 0.0279 & 0.0404 & 0 \\
\hline inadequate work pace during production & M4 & 0.1115 & 0.1686 & 0.2814 & 0 \\
\hline MACHINE & symbol & 11 & m1 & u1 & WEIGHT \\
\hline wrong machine parameters & M1 & 0.0158 & 0.0187 & 0.0280 & 0 \\
\hline exploited & M2 & 0.0701 & 0.1063 & 0.1874 & 0 \\
\hline old & M3 & 0.1006 & 0.1646 & 0.2547 & 0 \\
\hline vibrations & M4 & 0.1980 & 0.3006 & 0.4704 & 0,391753 \\
\hline loud machine work & M5 & 0.2728 & 0.4098 & 0.5811 & 0,608247 \\
\hline METHOD AND MATERIAL & symbol & 11 & m1 & u1 & WEIGHT \\
\hline $\begin{array}{l}\text { ill-chosen tools } \\
\end{array}$ & M1 & 0.0793 & 0.0921 & 0.1255 & 0 \\
\hline $\begin{array}{c}\text { contaminated tools } \\
\end{array}$ & M2 & 0.1066 & 0.1790 & 0.3119 & 0,108701 \\
\hline wrong parameters Production equipment & M3 & 0.2322 & 0.3261 & 0.4517 & 0,37373411 \\
\hline $\begin{array}{ll}\text { errors at work } \\
\end{array}$ & M4 & 0.2524 & 0.4028 & 0.6023 & 0,517564547 \\
\hline ENVIRONMENT & symbol & 11 & m1 & u1 & WEIGHT \\
\hline inadequate lighting & M1 & 0.1530 & 0.2200 & 0.3028 & 0,091967786 \\
\hline Pollution & M2 & 0.0247 & 0.0284 & 0.0411 & 0 \\
\hline Humidity & M3 & 0.2076 & 0.3262 & 0.5174 & 0,380807 \\
\hline Temperature & M4 & 0.2594 & 0.4254 & 0.6899 & 0,527225 \\
\hline MEASURE & symbol & 11 & m1 & u1 & WEIGHT \\
\hline bad measuring tools & M1 & 0.0904 & 0.1008 & 0.1277 & 0 \\
\hline Inaccurate & M2 & 0.5569 & 0.7999 & 1.1032 & 1 \\
\hline bad preparations & M3 & 0.0904 & 0.0993 & 0.1244 & 0 \\
\hline
\end{tabular}


Table 4.

Weighing the causes of the problem using the FAHP method

\begin{tabular}{|c|c|c|c|c|c|c|c|c|c|c|c|c|c|}
\hline & \multicolumn{3}{|c|}{ MAN } & \multicolumn{2}{|c|}{ MACHINE } & \multicolumn{2}{|c|}{ MANAGEMENT } & \multicolumn{2}{|c|}{$\begin{array}{l}\text { METHOD AND } \\
\text { MATERIAL }\end{array}$} & \multicolumn{2}{|c|}{ ENVIRONMENT } & \multicolumn{2}{|c|}{ MEASURE } \\
\hline & \multicolumn{3}{|c|}{$\mathrm{W}=[0,709 ; 1 ; 0,844 ; 0 ; 0,399]$} & \multicolumn{2}{|c|}{$\mathrm{W}=[0 ; 0 ; 0 ; 0,644 ; 1]$} & \multicolumn{2}{|c|}{$\mathrm{W}=[0,730 ; 1 ; 0 ; 0]$} & \multicolumn{2}{|c|}{$\mathrm{W}=[0 ; 0,210 ; 0,722 ; 1]$} & \multicolumn{2}{|c|}{$\mathrm{W}=[0,174 ; 0 ; 0,722 ; 1]$} & \multicolumn{2}{|c|}{$\mathrm{W}=[0 ; 1 ; 0]$} \\
\hline & & \multicolumn{2}{|c|}{$\begin{array}{l}\text { materiality } \\
\text { assessment }\end{array}$} & \multicolumn{2}{|c|}{$\begin{array}{c}\text { materiality } \\
\text { assessment }\end{array}$} & \multicolumn{2}{|c|}{$\begin{array}{l}\text { materiality } \\
\text { assessment }\end{array}$} & \multicolumn{2}{|c|}{$\begin{array}{c}\text { materiality } \\
\text { assessment }\end{array}$} & \multicolumn{2}{|c|}{$\begin{array}{l}\text { materiality } \\
\text { assessment }\end{array}$} \\
\hline $\mathrm{V}(\mathrm{M} 1 \geq \mathrm{M} 2)$ & \multirow{4}{*}{$\begin{array}{l}\mathrm{V}(\mathrm{M} 1 \geq \\
\text { M2, M3, } \\
\text { M4, M5) }\end{array}$} & 0,709 & \multirow{4}{*}{0,709} & 0 & \multirow{4}{*}{0} & 0,730 & \multirow{4}{*}{0,730} & 0,179 & \multirow{4}{*}{0} & 1 & \multirow{4}{*}{0,174} & 0 & \multirow{4}{*}{0} \\
\hline $\mathrm{V}(\mathrm{M} 1 \geq \mathrm{M} 3)$ & & 0,878 & & 0 & & 1 & & 0 & & 0,473 & & 1 & \\
\hline $\mathrm{V}(\mathrm{M} 1 \geq \mathrm{M} 4)$ & & 1 & & 0 & & 1 & & 0 & & 0,174 & & - & \\
\hline $\mathrm{V}(\mathrm{M} 1 \geq \mathrm{M} 5)$ & & 1 & & 0 & & - & & - & & - & & - & \\
\hline $\mathrm{V}(\mathrm{M} 2 \geq \mathrm{M} 1)$ & \multirow{4}{*}{$\begin{array}{l}\text { V(M2 } \geq \\
\text { M1, M3, } \\
\text { M4, M5) }\end{array}$} & 1 & \multirow{4}{*}{1} & 1 & \multirow{4}{*}{0} & 1 & \multirow{4}{*}{1} & 1 & \multirow{4}{*}{0,210} & 0 & & 1 & \\
\hline $\mathrm{V}(\mathrm{M} 2 \geq \mathrm{M} 3)$ & & 1 & & 0,598 & & 1 & & 0,351 & & 0 & 0 & 1 & 1 \\
\hline $\mathrm{V}(\mathrm{M} 2 \geq \mathrm{M} 4)$ & & 1 & & 0 & & 1 & & 0,210 & & 0 & 0 & - & 1 \\
\hline $\mathrm{V}(\mathrm{M} 2 \geq \mathrm{M} 5)$ & & 1 & & 0 & & - & & - & & - & & - & \\
\hline $\mathrm{V}(\mathrm{M} 3 \geq \mathrm{M} 1)$ & $\mathrm{V}(\mathrm{M} 3 \geq$ & 1 & & 1 & & 0 & & 1 & & 1 & & 0,958 & \\
\hline $\mathrm{V}(\mathrm{M} 3 \geq \mathrm{M} 2)$ & M1, M2, & 0,844 & & 1 & & 0 & & 1 & 0722 & 1 & 0722 & 0 & 0 \\
\hline $\mathrm{V}(\mathrm{M} 3 \geq \mathrm{M} 4)$ & M4, M5) & 1 & 0,844 & 0,294 & 0 & 0 & 0 & 0,722 & 0,122 & 0,722 & 0,122 & - & 0 \\
\hline V(M3 $\geq$ M5) & & 1 & & 0 & & - & & - & & - & & - & \\
\hline $\mathrm{V}(\mathrm{M} 4 \geq \mathrm{M} 1)$ & $\mathrm{V}(\mathrm{M} 4 \geq$ & 0 & & 1 & & 0,195 & & 1 & & 1 & & - & \\
\hline $\mathrm{V}(\mathrm{M} 4 \geq \mathrm{M} 2)$ & M1, M2, & 0 & & 1 & 0644 & 0 & & 1 & & 1 & & - & 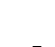 \\
\hline $\mathrm{V}(\mathrm{M} 4 \geq \mathrm{M} 3)$ & M3, M5) & 0 & 0 & 1 & 0,644 & 1 & 0 & 1 & 1 & 1 & 1 & - & - \\
\hline V(M4 $\geq M 5)$ & & 0 & & 0,644 & & - & & - & & - & & - & \\
\hline $\mathrm{V}(\mathrm{M} 5 \geq \mathrm{M} 1)$ & V(M5 $\geq$ & 0,693 & & 1 & & - & & - & & - & & - & \\
\hline $\mathrm{V}(\mathrm{M} 5 \geq \mathrm{M} 2)$ & M1, M2, & 0,399 & 0230 & 1 & 1 & - & & - & & - & & - & \\
\hline $\mathrm{V}(\mathrm{M} 5 \geq \mathrm{M} 3)$ & M3, M4) & 0,573 & 0,399 & 1 & 1 & - & - & - & - & - & - & - & - \\
\hline $\mathrm{V}(\mathrm{M} 5 \geq \mathrm{M} 4)$ & & 1 & & 1 & & - & & - & & - & & - & \\
\hline & um & & 2,952 & sum & 1,644 & sum & 1,729 & sum & 1,932 & sum & 1,897 & sum & 1 \\
\hline
\end{tabular}

